\title{
Using light-level geolocations to monitor incubation behaviour of a cavity-nesting bird Apus apus pekinensis
}

\author{
Xiao Huang, Yanyan Zhao and Yang Liu* (D)
}

\begin{abstract}
The Beijing Swift (Apus apus pekinensis) is a typical cavity-nesting bird that often nests inside holes and crevices in old architectures. Direct observation of their breeding behaviour is challenging and their breeding ecology is thus poorly studied. In this study, we analysed light-level geolocation data collected from six Beijing Swifts for the first time. Our results showed that geolocators can make comprehensive inference of their incubation period and behaviour. As a cost-effective and non-invasive method, geolocators can not only facilitate discovering migration routes, but also can be widely applied in the study of avian reproductive behaviour, especially in cavity-nesting bird species. We further discussed the characteristics and merits of this method and compared with other conventional nest-monitoring methods in recording birds.
\end{abstract}

\section{Correspondence}

Light level geolocator is a small apparatus that can track animal movements (Lisovski et al. 2012). It periodically records light-level data that can be used to calculate the coordinates of animals' locations. Due to low power and lightweight design, geolocators have been widely applied in bird migration studies, especially for those taxonomic groups, i.e. shorebirds, swifts and passerines, with light body mass (Bächler et al. 2010; Hedenström et al. 2013). As light level geolocators essentially use light sensors to record light-level data, they can be also employed to study incubation behaviour of some bird species that are shaded when incubating in their nests (Burger et al. 2012; Verhoeven et al. 2020). For instance, cavity-nesting species have contrasting light conditions in nests and ambient environments ( $\mathrm{Li}$ and Martin 1991). In other cases, if geolocators are mounted on legs of shorebirds and Anatidae, they can continuously log light-level changes and

*Correspondence: liuy353@mail.sysu.edu.cn

State Key Laboratory of Biocontrol, School of Ecology/School of Life

Sciences, Sun Yat-Sen University, Guangzhou 510275, China estimate incubation times and parental care of ground nesting birds (Burger et al. 2012; Verhoeven et al. 2020).

Cavity-nesting birds exploit a special ecology niche, including excavators and non-excavator species, in which species create cavities or occupy existing cavities. Previous studies suggested cavity-nesting birds exhibit contrasting life history traits, such as larger clutch size, longer nestling period and higher breeding success than open nesters (Martin and Li 1992; Martin 1993). Though breeding ecology of cavity-nesting birds have been globally studied, direct observations on parental care behaviour of excavators, however, are challenging, particularly in those species that occupy natural cavity nests. To tackle with this technical difficulty, light-level geolocators may well be a solution to illustrate some unappreciated aspects of breeding ecology of cavity-nesting birds.

In this study, we analysed geolocator data from a typical cavity-nesting bird, the Common Swift (Apus apus), to show that the usage of light-level geolocators can be a promising method to collect data of breeding behaviour of cavity-nesting birds. We especially focused on the subspecies pekinensis (termed as 'Beijing Swifts' hereafter) in a population breeding at Kuoru Pavilion $\left(39.9891^{\circ}\right.$ 
N, $116.2725^{\circ}$ E) of the Summer Palace, Beijing. Because Apus apus pekinensis breeds inside holes and crevices in old architectures, their breeding ecology and migration have not been comprehensively studied (Åkesson et al. 2012).

Between 2014 and 2016, geolocators were mounted on 66 individuals (31 individuals in 2014, 25 in 2015 and 10 in 2016, respectively) in order to track their migration routes. The model of geolocators was Intigeo-W65C1 made by Migrate Technology Ltd, weighed $0.65 \mathrm{~g}$. The total weight was around $1 \mathrm{~g}$ with attaching materials, approximately $2.7 \%$ of a swift's body weight. Therefore, the weight of the geolocator shall not affect survival of the birds (less than 4\%) (Higuchi et al. 1996). Geolocators were set to measure light level every minute and record the max for each 5-min period. The capture, recapture and data downloaded from geolocator have been done in a single day during the mid-term of a breeding season.

To obtain complete geolocation data of a breeding season, data collection should be spanned in two consecutive years. Due to the run-out of battery and single-capture, only data of six individuals can be used for further analyses of breeding ecology (Table 1).

We employed the $\mathrm{R}$ package Geolight (Lisovski et al. 2012) to transform the raw recording files. Light level is between 1 and 70,000 lx and thus all data have been logarithm. If the light level after transformation is lower than five, we regard it as a dark signal. Because there is an obvious gap around five in the density map of the light-level signals during the reproduction period (Fig. 1), which indicates a steep increase of light level caused by dark-light change. A dark signal represents that geolocator is shaded in the $5 \mathrm{~min}$. All statistical analyses were carried out with R 4.03 (R Core Team 2020).

The daily light-level change curve of Beijing Swifts drawn from geolocation data changes in different time through the year. For its extreme aerial life, the dark signal never appears during daytime in the migration. The earliest dark signals occurred during the daytime are in April, normally the time when Beijing Swifts arrive at their reproduction site (Additional file 1: Figure S1). These daytime dark signals reflect that swifts spend some time in their nests with dark condition, likely suggesting evidence of reproductive activities, such as nest-building, incubation and feeding nestlings. There are consistent patterns of daytime dark signal changes during breeding season, reflecting synchrony in breeding phenology and incubation patterns. Taking the individual M476 as an example (Additional file 1: Figure S1), the first daytime dark signal in 2015 appeared on May 7th. In advance to this date, the light level was high in whole day indicating the bird was still in migration. From May 9th to May 24th (above the red curve), the geolocators were occasionally shaded causing low light level in daytime. But the length of shaded periods was short, and the amount was also small. We referred this pattern as pre-incubation activities such as nest-building. Afterwards, we detected longer dark period increasingly during day time, lasting a 20-day period between May 25th and June 12th (the red curve). This likely suggests the onset of incubation period. After this period, short-duration shades occurred again, probably indicating nest provision was quite similar to the beginning of breeding season. If the incubation of M476 was successful, feeding nestlings can generate some shades in daytime. After July 15th, there were no more daytime shades suggesting fledging may leave the nest, and Beijing Swifts did not return their nests anymore. Thus, a breeding season must end after this date followed by the onset of migration season.

Light-level geolocator data can be analysed to illustrate a more precise division of reproduction periods after data transformation. In this study, we applied a criterion to define potential incubation bouts from the data, in which dark signals were continuous for a long period of time. The specific criterion applied to distinguish possible incubation bout is that the dark signals last for $30 \mathrm{~min}$ (six signals) with a break of light that is no longer than 5 min (one signal) (Gosbell et al. 2012). This criterion can avoid the impact of light/dark signals caused by accident rather than resulted from the birds' coming in/out of the

Table 1 The six Beijing Swifts with complete geolocation information of one reproduction season

\begin{tabular}{|c|c|c|c|c|}
\hline Ring number & Weight (lasted recapture) (g) & Capture year & Recapture year & $\begin{array}{l}\text { Year with full } \\
\text { breeding season } \\
\text { data }\end{array}$ \\
\hline M459 & 36.6 & 2014 & $2015 / 2016$ & 2015 \\
\hline M472 & - & 2014 & 2016 & 2015 \\
\hline M476 & 35.5 & 2014 & $2015 / 2016$ & 2015 \\
\hline Z680 & 37 & 2016 & 2018 & 2017 \\
\hline Z682 & 35 & 2016 & $2017 / 2018$ & 2017 \\
\hline Z683 & 38 & 2016 & 2018 & 2017 \\
\hline
\end{tabular}




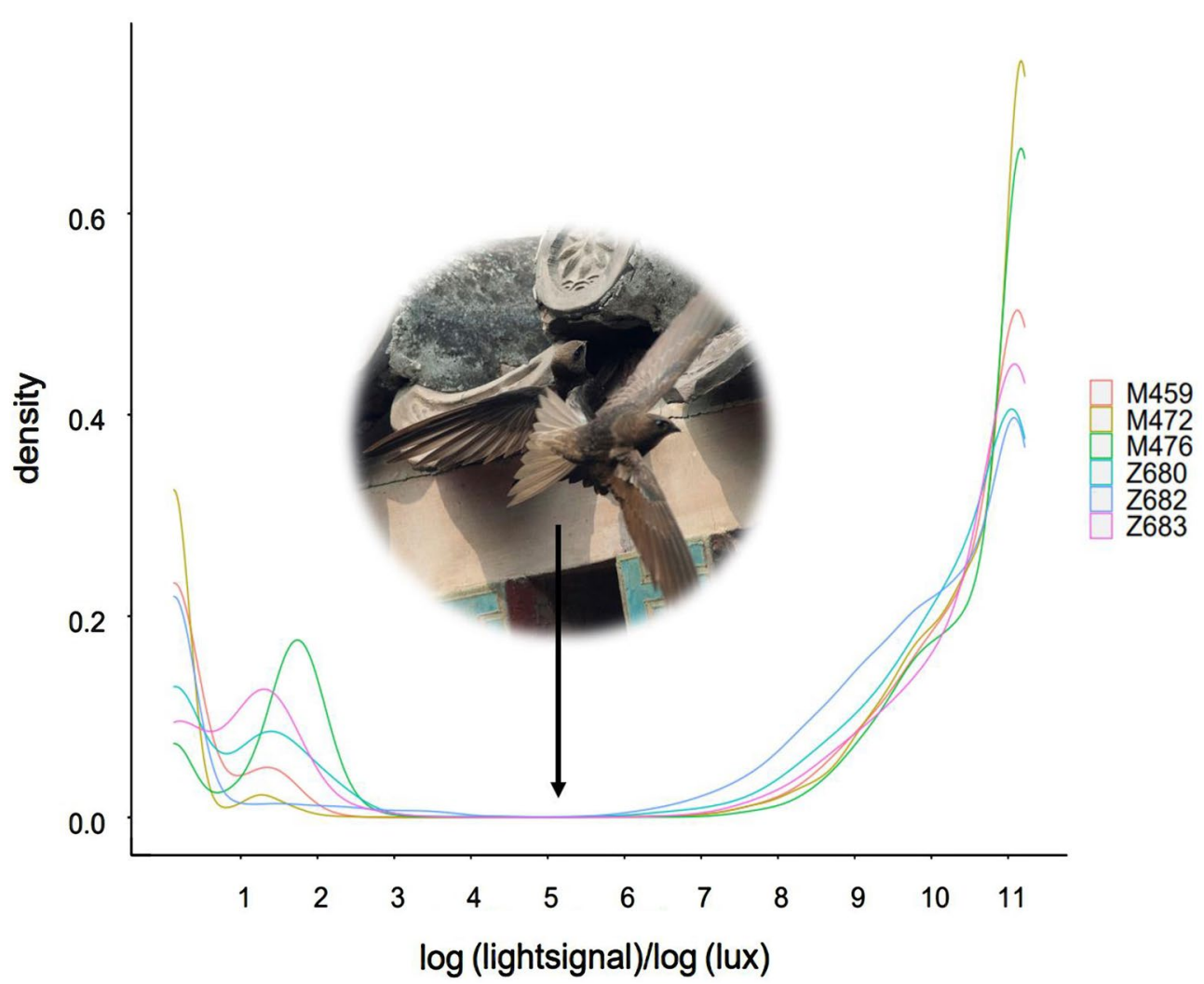

Fig. 1 The density curve of light signals collected in the reproduction period of six Beijing Swifts. The $x$ axis shows light level (after log transformation), and the $y$ axis shows the percentage of light signals that is in each level. The photo (Photographed by Yu Zhang at Summer Palace, Beijing) shows Beijing Swifts come in and out of a cavity nest, which generates steep change of light level

nest. Between May and July, the length of daytime in Beijing is about $14-15 \mathrm{~h}$. Sunrise is ranged from 4:45 a.m. to 5:37 a.m. while sunset is 7:19 p.m. to 8:18 p.m. We define 6:00 a.m. to 7:00 p.m. as daytime and only included data during this period.

Although the potential incubation bouts exist in the whole breeding season after shifting, we can manually identify the beginning and end of an individual's incubation period (Verhoeven et al. 2020) and they can be used to infer parental care efforts during incubation. The referring is mainly based on following assumptions. First, birds incubate every day during incubation period, and thus the possible incubation bout also exists every day in this period. Second, male and female birds take turn to incubate as our samples contain both male and female individuals, suggesting biparental care in swifts (Carere and Alleva 1998). So, there should be more than one possible incubation bout of every individual for each day during incubation. Finally, the total time of daytime shades every day should be more than a threshold. The threshold we adopted is $250 \mathrm{~min}$ (50 signals). We divided the entire reproduction period for all six individuals. Then we compared the length of incubation bouts and accounted of incubation per day in different reproduction periods using Linear Mixed Model (LMM) in R package lme4 (Bates et al. 2014). All birds showed a clear period of incubation in which potential incubation bouts were significantly longer every day (Fig. 2). To sum up, Beijing Swifts started incubation in early May and ended in early July except M476 in this study (Fig. 3; Additional file 2: Table S1), which started incubation on May 28th, 2015 when some individuals had even ended their incubation. According to the geolocation data, the incubation lasted for 21 days (Additional file 2: Table S1) on average for the six individuals in our study, which is similar to previous studies in other locations of China by direct observation (Wang 1958).

One main limitation of this method is from pre-incubation and post-incubation behaviour, e.g. nest repairing and chick provisioning can also cause daytime shade. Sometimes these shades are long so it is difficult to distinguish them from daytime shade resulted from incubation behaviour. This makes a challenge when inferring the onset and end of incubation period. Our manual criterion might partly solve this problem. Using this criterion strictly, our inferred incubation period shows similar 

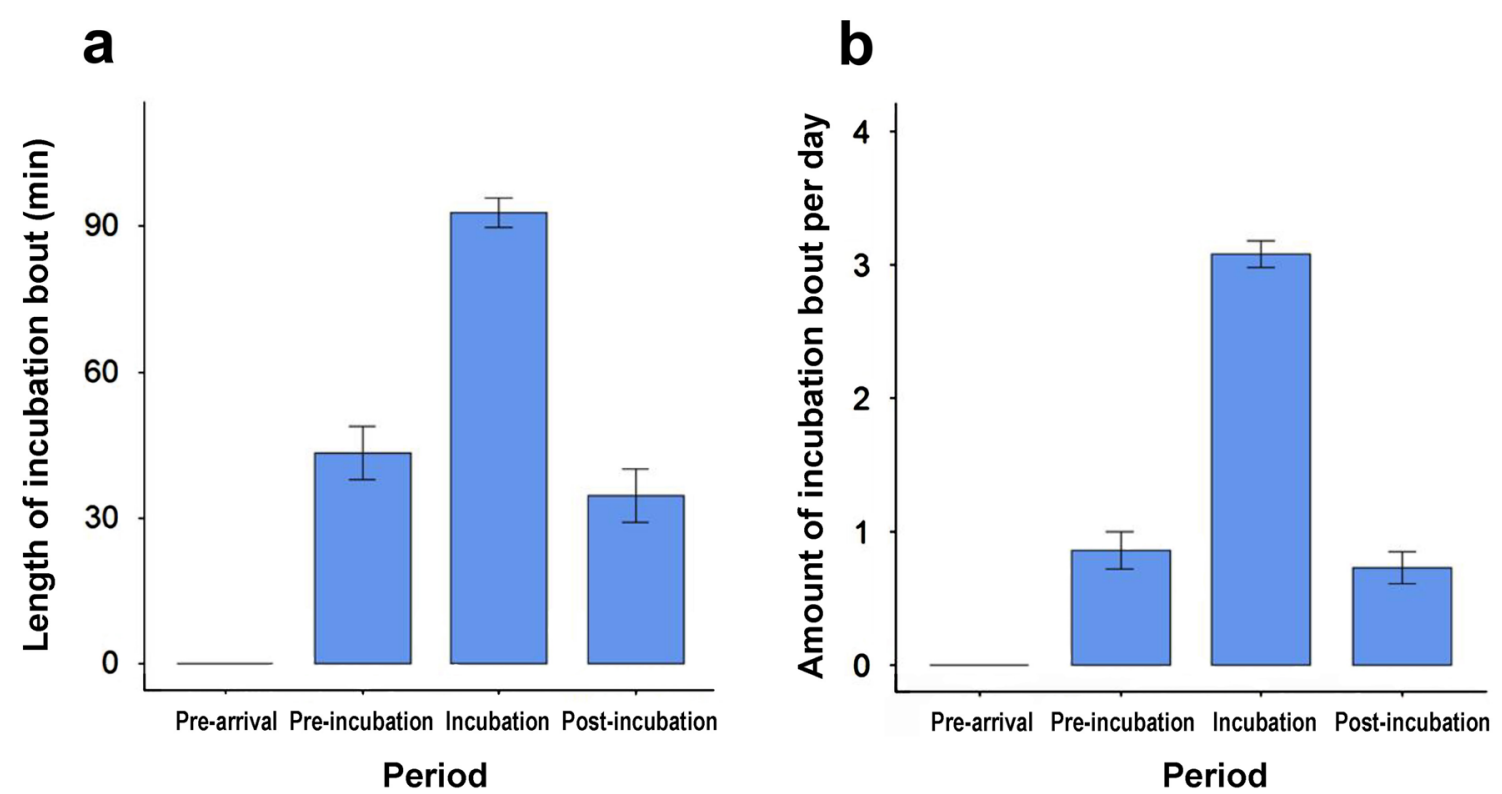

Fig. 2 Bar plot shows the result of Linear Mixed Model in which length and amount of incubation bouts were modelled as a function of reproduction period. The $y$ axis indicates of $\mathbf{a}$ length of incubation bout, $\mathbf{b}$ amount of incubation bout per day for all the individuals (mean \pm SE represents in bars)

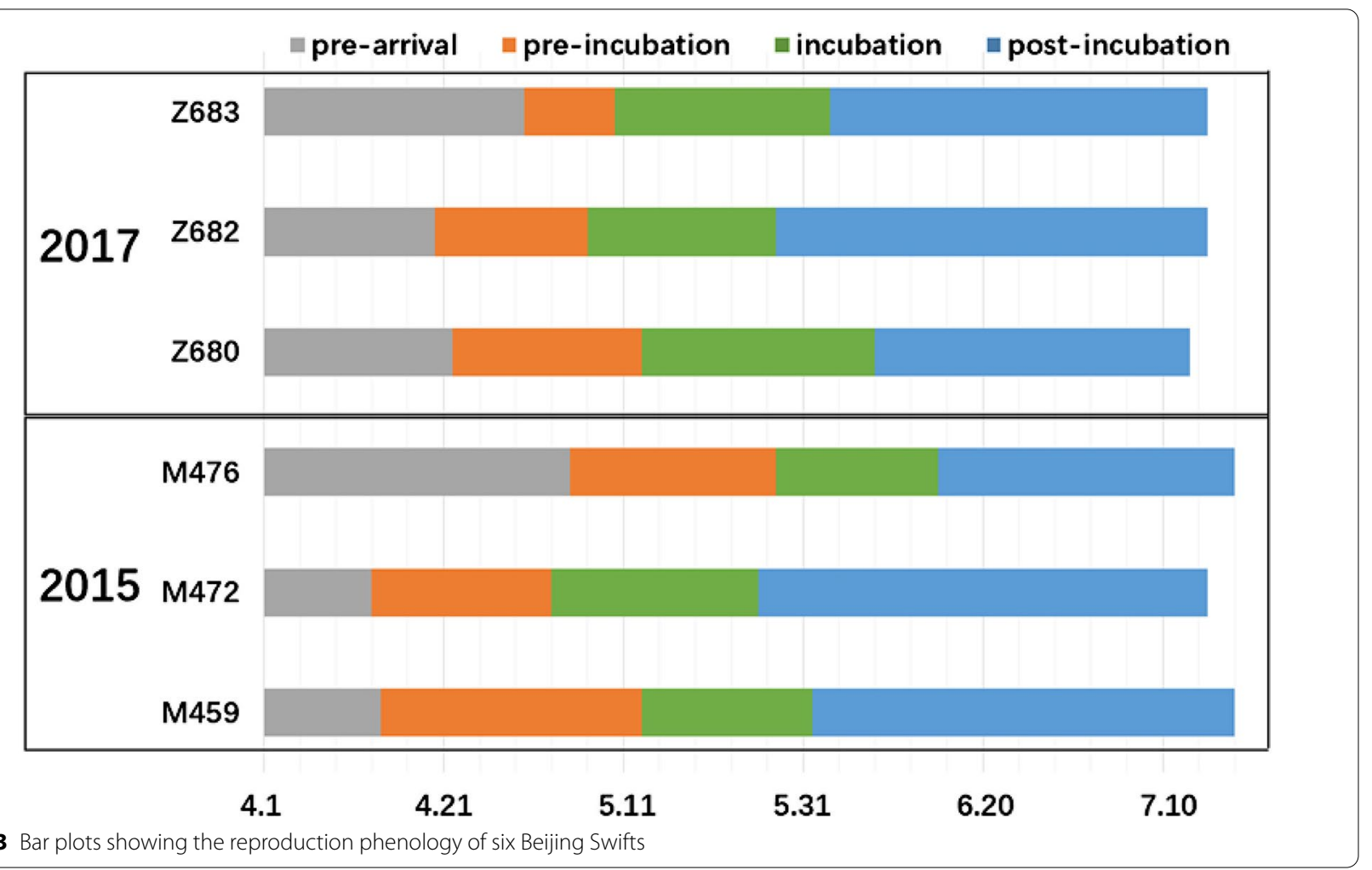

length with previous studies by direct observation (Wang 1958), and has significant longer and more incubation bouts. It can be more accurate to obtains the onset and end date of incubation by nest checking in a few days before the start and end of incubation if possible. 
Though we obtained a small sample size, our study shows that light-level geolocators are able to record incubation behaviours of the Beijing Swifts. This method can also be employed in other cavity-nesting birds that are shaded when incubating in their nest. Compared with conventional nest-monitoring methods, i.e. infrared cameras or webcam, the usage of light-level geolocators has several advantages. First, geolocators have a long lifetime thus can record the incubation behaviour continuously during a whole breeding season, while recording cameras can only record for several days before running out of power (Burnham and Cruz-Bernate 2020), or require external electronic power supply. And because the resulting data files are very small, geolocator's own memory is sufficient to handle large amounts of data over a long period. Second, geolocators can be applied to a large number of individuals at the same time, owing to its low cost ( 200 USD) and easy data processing. Data derived from cameras usually require huge efforts to process and annotate, especially when it records many individuals over a long period. Finally, the geolocators cause little disturbance to adult birds during breeding season for their enough small size (Åkesson et al. 2012). Sometimes additional measures need to be applied to reduce the significant disturbance from setting recording cameras (de Moraes et al. 2020). Nevertheless, long endurance capability of geolocators avoids multiple nest visits for equipment maintenance by researchers.

Thanks to these general advantages aforementioned, this method is particularly suitable for cavity-nesting birds occupying tree cavity (e.g. woodpeckers), burrow (e.g. kingfishers) and artificial cavity (e.g. swifts and swiftlets). On the one hand, cavity-nesting birds are consistently shaded when incubating. Hence the geolocators can record the incubation behaviour more precisely. When using geolocators to record the incubation of open-nesting species such as shorebirds, there are usually some breaks of shading within an incubation session because the bird stands to change position in the nest (Burger et al. 2012; Verhoeven et al. 2020). On the other hand, it is often difficult to set up and maintain recording camera for cavity-nesting birds, e.g., most cavity-nesting birds prefer to nest in caves of high trees in the forest (Bonaparte et al. 2020) or cliffs, which are difficult to approach.

Bird species using cavity nests account for a large proportion across avian kingdom, e.g. at least 1878 species (18.1\% of all bird species in the world) nest in tree cavities (van de Hoek et al. 2017). Groups of cavity-nesting birds are tightly associated with the phylogenies, i.e. the large branch of land birds defined as 'Cavitaves' (rollers, woodpeckers, hornbills, trogons, cuckoo rollers and mousebirds), Muscicapoidea (e.g. Muscicapidae and Sturnidae), Certhoidea (e.g. Sittidae, Certhidae, Troglodytidae and
Paridae) and some Passeridea of passerines. We believe that light-level geolocators can be more widely used on cavity-nesting birds for documenting their incubation behaviour.

\section{Supplementary Information}

The online version contains supplementary material available at https://doi. org/10.1186/s40657-021-00245-w.

Additional file 1: Figure S1. Daily light level change of all six individuals of Beijing Swift in the reproduction period. Figure S2. Box plots of possible incubation bouts in the whole breeding season of six Beijing Swifts.

Additional file 2: Table S1. The specific onset and end date of different reproduction period of six individuals of Beijing Swifts inferred from lightlevel geolocators.

\section{Acknowledgements}

We are grateful to all the volunteers taking part in the field work, and Dick Newell of Action for Swifts, Susanne Åkesson of Lund University, and Migrate Technology Ltd for providing the geolocators. We also appreciate the support from Management office of Summer Palace and Beijing Wildlife Rescue \& Rehabilitation Center, and the help from National Bird Banding Center of China and Beijing Bird Banding Station.

\section{Authors' contributions}

$\mathrm{YL}$ conceived and designed the study. $\mathrm{XH}$ and $\mathrm{YZ}$ performed the data analyses and wrote the manuscript with inputs by $Y L$. All authors read and approved the final manuscript.

Funding

This project was funded by SHAN SHUI Conservation Centre, Beijing.

Availability of data and materials

The datasets used in the present study are available from the corresponding author on reasonable request.

\section{Declarations}

Ethical approval and consent to participate standards

This article does not contain any studies with human participants performed by any of the authors. The experiments comply with the current laws of China. Bird capturing and tagging was approved by Beijing Gardening and Greening Bureau.

\section{Consent for publication}

Not applicable.

\section{Competing interests}

The authors declare that they have no competing interests.

Received: 29 December 2020 Accepted: 23 February 2021

Published online: 06 March 2021

\section{References}

Åkesson S, Klaassen R, Holmgren J, Fox JW, Hedenström A. Migration routes and strategies in a highly aerial migrant, the common swift Apus apus, revealed by light-level geolocators. PLoS ONE. 2012;7:e41195. https://doi. org/10.1371/journal.pone.0041195.

Bächler E, Hahn S, Schaub M, Arlettaz R, Jenni L, Fox JW, et al. Year-round tracking of small trans-Saharan migrants using light-level geolocators. PLoS ONE. 2010;5:e9566. https://doi.org/10.1371/journal.pone.0009566.

Bates D, Mächler M, Bolker B, Walker S. Fitting linear mixed-effects models using Ime4. J Stat Softw. 2014;67:1-48. https://doi.org/10.18637/jss.v067. i01. 
Bonaparte EB, Ibarra JT, Cockle KL. Conserving nest trees used by cavitynesting birds from endangered primary Atlantic forest to open farmland: increased relevance of excavated cavities in large dead trees on farms. For Ecol Manag. 2020;475:118440. https://doi.org/10.1016/j.forec 0.2020 .118440 .

Burnham H, Cruz-Bernate L. Parental investment does not directly affect reproductive success in the saffron finch. J Avian Biol. 2020. https://doi. org/10.1111/jav.02489.

Burger J, Niles LJ, Porter RR, Dey AD. Using geolocator data to reveal incubation periods and breeding biology in Red Knots Calidris canutus rufa. Wader Stud Group Bull. 2012;119:26-36. https://doi.org/10.1016/j. ajog.2004.10.607.

Carere C, Alleva E. Sex differences in parental care in the common swift (Apus apus): effect of broad size and nestling age. Can J Zool. 1998;76:13827. https://doi.org/10.1139/z98-073.

de Moraes PZ, Diniz P, Macedo RH. Sex-specific effects of predation risk on parental care in a sexually dichromatic Neotropical songbird. J Avian Biol. 2020. https://doi.org/10.1111/jav.02483.

Gosbell K, Minton C, Fox J. Geolocators reveal incubation and re-nesting characteristics of Ruddy Turnstones Arenaria interpres and Eastern Curlews Numenius madagascariensis. Wader Stud Group Bull. 2012;119:160-71.

Hedenström A, Klaassen RHG, Åkesson S. Migration of the Little Ringed Plover Charadrius dubius breeding in South Sweden tracked by geolocators. Bird Study. 2013;60:466-74. https://doi.org/10.1080/00063657.2013.843635.

Higuchi H, Ozaki K, Fujita G, Minton J, Ueta M, Soma M, et al. Satellite tracking of White-naped Crane migration and the importance of the Korean demilitarized zone. Conserv Biol. 1996;10:806-12. https://doi.org/10.104 6/j.1523-1739.1996.10030806.x.
Li P, Martin TE. Nest-site selection and nesting success of cavity-nesting birds in high elevation forest drainages. Auk. 1991;108:405-18. https://doi. org/10.1093/auk/108.2.405

Lisovski S, Hewson CM, Klaassen RHG, Korner-Nievergelt F, Kristensen MW, Hahn S. Geolocation by light: accuracy and precision affected by environmental factors. Methods Ecol Evol. 2012;3:603-12. https://doi. org/10.1111/j.2041-210X.2012.00185.X.

Martin TE. Evolutionary determinants of clutch size in cavity-nesting birds: nest predation or limited breeding opportunities? Am Nat. 1993;142:93746. https://doi.org/10.1086/285582.

Martin TE, Li P. Life history traits of open-vs. cavity-nesting birds. Ecology. 1992;73:579-92. https://doi.org/10.2307/1940764.

R Core Team. R: a language and environment for statistical computing. Vienna, Austria: R Foundation for Statistical Computing. 2020. https://www.Rproject.org/.

van de Hoek Y, Gaona GV, Martin K. The diversity, distribution and conservation status of the tree-cavity-nesting birds of the world. Divers Distrib. 2017;23:1120-31. https://doi.org/10.1111/ddi.12601.

Verhoeven MA, Loonstra AHJ, McBride AD, Macias P, Kaspersma W, Hooijmeijer JCEW, et al. Geolocators lead to better measures of timing and renesting in black-tailed godwits and reveal the bias of traditional observational methods. J Avian Biol. 2020;51:e02259. https://doi.org/10.1111/jav.02259.

Wang XT. The primary study on the ecology of "Beijing Swifts" in Lanzhou. Bull Biol. 1958;7:15-8 (in Chinese).
Ready to submit your research? Choose BMC and benefit from:

- fast, convenient online submission

- thorough peer review by experienced researchers in your field

- rapid publication on acceptance

- support for research data, including large and complex data types

- gold Open Access which fosters wider collaboration and increased citations

- maximum visibility for your research: over 100M website views per year

At BMC, research is always in progress.

Learn more biomedcentral.com/submissions 